cost-effective mortality reduction. J Thorac Cardiovasc Surg. 2020;160: 675-86.e13.

6. Badhwar V, Rankin JS, Damiano RJ, Gillinov AM, Bakaeen FG, Edgerton JR, et al. The Society of Thoracic Surgeons 2017 clinical practice guidelines for the surgical treatment of atrial fibrillation. Ann Thorac Surg. 2017;103:329-41.
7. Ad N, Damiano RJ Jr, Badhwar V, Calkins H, La Meir M, Nitta T, et al. Expert consensus guidelines: examining surgical ablation for atrial fibrillation. J Thorac Cardiovasc Surg. 2017;153:1330-54.e1.

8. Calkins H, Hindricks G, Cappato R, Kim YH, Saad EB, Aguinaga L, et al. 2017 HRS/EHRA/ECAS/APHRS/SOLAECE expert consensus statement on catheter and surgical ablation of atrial fibrillation. Heart Rhythm. 2017;14:e275-444.
See Article page 980.

\section{Commentary: What would Sir Francis Bacon think of us now?}

\author{
Alden H. Harken, MD
}

At the beginning of the seventeenth century, "science" was awash in superstition, unguided speculation, and theology. Voltaire famously credited Francis Bacon with the concept and development of the "scientific method." Bacon proposed that with a thoughtful perusal of facts, one could induce a unifying hypothesis and deduce the validity of that hypothesis by rigorous challenge with facts. Descartes took the next step by declaring that knowledge is created by the progression from one clear idea to the next. A century later, Hegel posited that knowing and the essence of reality must coincide. So, it was a small step for Kierkegaard, in the following century, to criticize rational knowledge stating that "truth is subjectivity," anticipating William James, who wrote that truth is not the quality of an idea, conversely "truth is made by an act of will."

In the accompanying manuscript, a conscientious group of investigators have assessed the beneficial and adverse effects of catheter ablation and surgical ablation of atrial fibrillation. ${ }^{1}$ Atrial fibrillation is a common clinical problem. Both surgical ablation and catheter ablation are frequently administered therapies. Therefore, the authors are asking a practical and important question. Fortunately, there is a wealth of information published on this topic. By scouring the medical literature, the authors identified

From the UCSF-East Bay (retired), Alamo, Calif.

Disclosures: The author reported no conflicts of interest.

The Journal policy requires editors and reviewers to disclose conflicts of interest and to decline handling or reviewing manuscripts for which they may have a conflict of interest. The editors and reviewers of this article have no conflicts of interest.

Received for publication May 21, 2020; accepted for publication May 21, 2020; available ahead of print June 5, 2020.

Address for reprints: Alden H. Harken, MD, Department of Surgery, University of California, San Francisco, East Bay, 1565 Alamo Way, Alamo, CA 94602 (E-mail: alden.harken68@gmail.com).

J Thorac Cardiovasc Surg 2022;163:996-7 $0022-5223 / \$ 36.00$

Copyright $₫ 2020$ Published by Elsevier Inc. on behalf of The American Association for Thoracic Surgery

https://doi.org/10.1016/j.jtcvs.2020.05.072
Check for updates

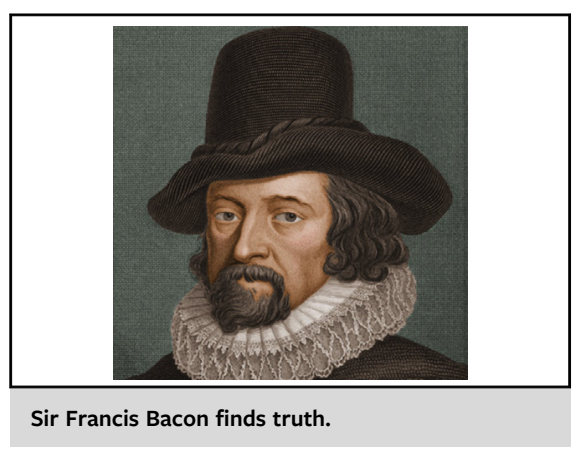

CENTRAL MESSAGE

Metaphysics is "kind of" physics;

however, you can't prove it. A

meta-analysis provides the au-

thor's opinion, but again, they

can't prove it.

2810 studies addressing this issue. By scanning these manuscripts, they were able to cull 2748, leaving 62 eligible studies. Critical examination of these manuscripts further depleted the investigations examined down to 7 analyses of 583 patients. Clinical investigation is hard to do, and it is even harder to do well. The 2810 manuscripts are available to everyone. Selecting 7 studies of 2810 requires a huge amount of work.

Cognitive assumptions can distort our observations and even influence our conclusions. We think of bias in a pejorative way; however, it is hard to imagine a decision that anyone ever makes that is not biased. When we must acknowledge this pre-judgmental influence, we call it experience. The Cochrane Collaboration has plowed a lot of scholarly energy into the domains of bias, and they categorize the varieties as selection, performance, detection, attrition, and reporting biases. Imagine, for instance, that you randomly (the word itself sounds pretty good) empanel your jury from a group of people phoning in for a tee time at Mar-A-Lago versus a group (again randomly) 
selected from an Elizabeth Warren fundraiser; or from a barbeque in Texas versus a wine tasting in Napa; or even (God forbid) from a gaggle of cardiologists versus a pride of cardiac surgeons. How mind-bending is the step from Bacon and Hegel and William James to our current state of scientific inquiry nestled within the comfortable confines of the Journal?

In the accompanying manuscript, after carving the thousands of investigations down to a bite-sized 7 , the authors note that in 6 of the 7 the confidence limits statistically favor surgery and in aggregate they document a 1.7 -fold superiority of surgical ablation. The authors note that they were using a strategy that prioritize "sensitivity" over "precision" maximizing. Kierkegaard would have smiled at their recognition of "subjectivity" and that "feelings do matter!" The
American Association for Thoracic Surgery and the Society of Thoracic Surgeons have consistently favored surgery with a Class I recommendation. Currently, with identical data available, the Heart Rhythm Society and the American Heart Association/American College of Cardiology (confidently applying the traditional "I want my kid to win" philosophy) have wobbled back and forth with surgery as Class I and IIa recommendations. What's going on? Is it OK for us to draw the bull's eye around the tip of our arrow after we have shot and hit the barn door?

\section{Reference}

1. Huang H, Wang Q, Xu J, Wu Y, Xu C. Comparison of catheter and surgical ablation for atrial fibrillation: a systemic review and meta-analysis of randomized trials. J Thorac Cardiovasc Surg. 2022;163:980-93.
See Article page 980.

\section{Commentary: Achieving success after ablation for atrial fibrillation: It's what you do and not how you do it}

\author{
Harold L. Lazar, MD
}

In this edition of the Journal, Huang and co-workers ${ }^{1}$ report the results of a meta-analysis comparing the absence of atrial fibrillation (AF) over a 12-month period without antiarrhythmic medications in patients undergoing catheter ablation (CA) versus surgical ablation (SA). They concluded that SA "conferred a moderate advantage" over $\mathrm{CA}$ in patients with paroxysmal AF and persistent longstanding AF. The meta-analysis consisted of 7 randomized controlled trials (RCTs) involving 583 patients. The SA group had 6 studies in which pulmonary vein isolation (PVI) was performed using thoracoscopic techniques. In 1

\footnotetext{
From the Division of Cardiac Surgery, Boston University School of Medicine, Boston, Mass.

Disclosures: The author reported no conflicts of interest.

The Journal policy requires editors and reviewers to disclose conflicts of interest and to decline handling or reviewing manuscripts for which they may have a conflict of interest. The editors and reviewers of this article have no conflicts of interest.

Received for publication May 14, 2020; accepted for publication May 14, 2020; available ahead of print June 5, 2020.

Address for reprints: Harold L. Lazar, MD, 80 East Concord St, Boston, MA 02118 (E-mail: harold.1.lazar@gmail.com).

J Thorac Cardiovasc Surg 2022;163:997-9

$0022-5223 / \$ 36.00$

Copyright (c) 2020 by The American Association for Thoracic Surgery

https://doi.org/10.1016/j.jtcvs.2020.05.069
}

Check for updates

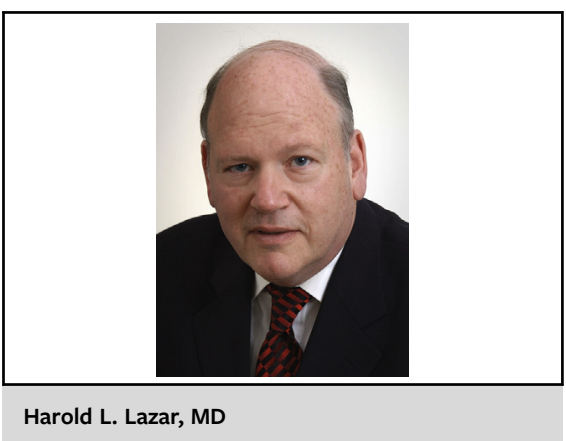

CENTRAL MESSAGE

Achieving success after ablation

for AF is dependent on what

lesion sets you do and not how

you do them.

trial, patients were randomized to CA or SA 6 months after valve surgery. All lesion sets were performed using radiofrequency (RF) techniques. None of the patients had a full Cox Maze IV lesion set involving the right atrium (RA) and left atrium (LA), and no mention is made of the use of LA appendage (LAA) ablation techniques. Femoral vascular complications were more common in patients receiving $\mathrm{CA}$, and there was a higher incidence of pneumothorax in the SA group. There was no difference in 